\title{
BIOLOGICAL CONTROL: CORNERSTONE OF AREA- WIDE-INTEGRATED PEST MANAGEMENT FOR THE CASSAVA MEALYBUG IN TROPICAL ASIA
}

\author{
K. A. G. WYCKHUYS ${ }^{1}$, W. ORANKANOK ${ }^{2}$, J. W. KETELAAR ${ }^{3}$, \\ A. RAUF ${ }^{4}$, G. GOERGEN ${ }^{5}$ AND P. NEUENSCHWANDER ${ }^{5}$ \\ ${ }^{1}$ CGIAR Research Program on Roots, Tubers and Banana (CRP-RTB), International \\ Center for Tropical Agriculture CIAT, Hanoi,Viet Nam; kagwyckhuys@gmail.com \\ ${ }^{2}$ Department of Agricultural Extension, Bangkok, Thailand \\ ${ }^{3}$ Food and Agriculture Organization (FAO), Bangkok, Thailand \\ ${ }^{4}$ Bogor Agricultural University, Bogor, Indonesia \\ ${ }^{5}$ International Institute of Tropical Agriculture (IITA), Cotonou, Benin
}

\begin{abstract}
SUMMARY
The cassava mealybug Phenacoccus manihoti Mat.-Ferr. (Hemiptera: Pseudococcidae) is a globally important pest of cassava (Manihot esculenta Crantz), a crop that is cultivated on nearly 25 million ha across the tropics. Following its continent-wide invasion of Africa during the 1970s and early 1980s, $P$. manihoti was inadvertently introduced to Southeast Asia in late 2008, where it caused important yield drops in local crops. Guided by the widely-acclaimed biological control successes against this mealybug in Africa, the endophagous parasitoid Anagyrus lopezi De Santis (Hymenoptera: Encyrtidae) was introduced to Thailand in 2009. Subsequent introductions of $A$. lopezi were made into neighbouring countries, and an integrated campaign was launched to scale-up mealybug biological control. Multi-country field surveys were carried out to map P. manihoti geographic distribution, field-level abundance and extent of parasitoidmediated suppression, and innovative extension programmes were deployed to raise farmer awareness of mealybug pests and associated natural enemies. Survey work from nearly 600 fields throughout mainland Southeast Asia revealed that $P$. manihoti occurred at abundance levels of $14.3 \pm 30.8$ individuals per tip in the dry-season, and A. lopezi parasitism averaged at 38.9\%. An applied research programme yielded critical insights into various determinants of $A$. lopezi establishment, spread and biological control efficacy. In close collaboration with national partners, research was carried out on the eventual effects of soil fertility and plant nutrition, landscape composition, and a plant's phytopathogen infection status, amongst others. Our work shows how the host-specific $A$. lopezi effectively suppresses the cassava mealybug across a range of agro-climatic, biophysical and socio-economic contexts in tropical Asia, and constitutes a central component of area-wide integrated pest management (AW-IPM) for this global pest invader. This study also underlines the need for holistic, transdisciplinary approaches to (invasive) pest management, and the tangible yet (largely) untapped potential of coupling social and biological sciences to address crop protection problems in the developing-world tropics.
\end{abstract}

J. Hendrichs, R. Pereira and M. J. B. Vreysen (eds.), Area-Wide Integrated Pest Management: Development and Field Application, pp. 17-32. CRC Press, Boca Raton, Florida, USA.

(C) 2021 IAEA 
Key Words: Classical biological control, ecosystem services, invasive species management, food security, landscape diversity, natural enemy, trophic ecology, tropical agriculture, Manihot esculenta, Phenacoccus manihoti, Anagyrus lopezi

\section{INTRODUCTION}

Cassava mealybug Phenacoccus manihoti Mat.-Ferr. (Hemiptera: Pseudococcidae) is a prominent herbivore on cassava (Manihot esculenta Crantz) and one of the world's most notorious invasive species. Endemic to the Paraguay River basin in South America, P. manihoti was inadvertently introduced into Africa during the early 1970s and rapidly spread across the continent's extensive cassava belt (Herren and Neuenschwander 1991; Bellotti et al. 2012). Capable of inflicting yield losses up to 58-84\% (Nwanze 1982; Schulthess et al. 1991), P. manihoti devastated local cassava production and caused widespread hunger for farming families across sub-Saharan Africa.

In late 2008, this same pest was detected in Thailand's eastern seaboard, where it caused an $18 \%$ drop in aggregate crop yield of cassava, a yearly loss of over 8 million ton fresh root in Thailand alone, and more than 2-fold surges in prices of cassava starch (Muniappan et al. 2009; Wyckhuys et al. unpublished). By 2011, P. manihoti had spread extensively in Thailand and had inflicted economic losses on the country's cassava sector of over USD 30 million nationally (TTTA 2011).

In 2014, $P$. manihoti had also entered prime cassava growing areas in neighbouring Cambodia, Indonesia, Lao PDR, Malaysia, and Viet Nam (Sartiami et al. 2015; Graziosi et al. 2016). Climate-based niche modelling revealed that other key cassava production areas in eastern Indonesia and the Philippines are also at risk to $P$. manihoti (Yonow et al. 2017). As Southeast Asia accounts for nearly 95\% of the world's cassava exports and is home to a multi-billion-dollar cassava starch industry (Cramb et al. 2017), P. manihoti was expected to inflict major socio-economic impacts at a regional level.

\subsection{Control of Cassava Mealybug in Africa}

Though this mealybug invader evidently posed an immediate threat to the rural economy of several Asian countries, a nearly tailor-made management solution had been successfully developed in Africa more than thirty years ago. In fact, after the 1980 discovery of P. manihoti in Paraguay by A. Bellotti (International Center for Tropical Agriculture, CIAT), one of the world's best-known and successful insect classical biological control programmes was initiated (Bellotti et al. 1999; Neuenschwander 2001). In 1981, the Centre for Agriculture and Bioscience International (CABI) and the International Institute of Tropical Agriculture (IITA) teamed up to carry out foreign exploration in the presumed region of origin of $P$. manihoti, ultimately resulting in the collection and subsequent shipment of the Anagyrus lopezi De Santis (Hymenoptera: Encyrtidae) (Löhr et al. 1990).

Following its 1981 release in western Nigeria, A. lopezi promptly established and suppressed $P$. manihoti population levels from more than 100 to fewer than 10-20 individuals per cassava tip (Hammond et al. 1987). In less than three years following its release, A. lopezi had effectively dispersed over $200000 \mathrm{~km}^{2}$ in south-western 
Nigeria. It had also been mass-reared and distributed across multiple release points in several African countries (Herren et al. 1987). Though multiple endemic primary parasitoids and hyperparasitoids were recorded in mealybug-invaded areas in Africa (Neuenschwander et al. 1987; Neuenschwander and Hammond 1988), these largely did not impede the success of $A$. lopezi as a biological control agent.

Overall, the parasitoid wasp successfully established in 26 African countries, prevented wide-spread famine and generated economic benefits of USD 9400-20 200 million (Zeddies et al. 2001). Moreover, across the highly diverse and vast African continent, no agro-ecological conditions were found under which $A$. lopezi was unable to establish and attack its mealybug host (Neuenschwander 2001).

\subsection{Cassava Mealybug in Southeast Asia}

Soon after its detection in Asia, Thailand's late Amporn Winotai of the Department of Agriculture (DoA) solicited assistance from CIAT's Anthony Bellotti to tackle the fast-spreading mealybug pests in her country. Well aware of the accomplishments in Africa, A. Bellotti rightly pointed Thai colleagues to G. Goergen and P. Neuenschwander at the IITA station in Cotonou, Benin. In late 2009, A. lopezi was then effectively introduced from West Africa into Thailand, and rearing labs were established in different parts of the country, through a joint endeavour between the Food and Agriculture Organization of the United Nations (FAO), centres of the Consultative Group on International Agricultural Research (CGIAR), and Thailand's Royal Government (Winotai et al. 2010).

The A. lopezi releases received ample public attention and quickly culminated in an unprecedented, nation-wide campaign to mass-rear and distribute wasps, in which government institutions, grower associations and private sector actors, such as the Thai Tapioca Development Institute (TTDI), all joined forces. Within the context of a regional technical cooperation project, mass-releases of $A$. lopezi were carried out across Thailand, some of which by airplane, and were followed by FAO-led introductions into Cambodia, Lao PDR and Viet Nam. The 2014 release of several hundred A. lopezi pairs into Indonesia were enabled by A. Rauf at Bogor Agricultural University (Wyckhuys et al. 2015). All these parasitoid introductions and capacity building interventions were implemented with the Royal Thai Government Ministry of Agriculture and Cooperatives' technical assistance, most notably from key IPM experts in its Department of Agriculture (DoA) and Department of Agricultural Extension (DoAE).

Other methods promoted for $P$. manihoti control include neonicotinoid stake dips (e.g. Parsa et al. 2012) and mass-releases of laboratory-reared predators and entomopathogens (Saengyot and Burikam 2012; Sattayawong et al. 2016). Despite the above efforts to promote a wide range of chemical and biologically-based management tactics, it is widely thought that it is $A$. lopezi that suppressed cassava mealybug populations across mainland Southeast Asia.

In this paper, we provide an in-depth assessment of $P$. manihoti population pressure and Asia-wide distribution, report on the establishment and spatial spread of the introduced $A$. lopezi, and examine biophysical, agro-climatic, and social factors that might enhance or impede mealybug biological control. 


\section{MAPPING MEALYBUG DISTRIBUTION}

Until the appearance of $P$. manihoti in Asia's cassava fields, there was only scant and scattered information about the nature, distribution, etiology, epidemiology and ecology of the primary phytosanitary constraints of this crop in Southeast Asia (Bellotti et al. 2012; Graziosi and Wyckhuys 2017). In late 2013 though, an ambitious surveillance programme was set up together with international and national partners in Cambodia, Lao PDR, Myanmar, southern China, Thailand, and Viet Nam. With backstopping through the late Prabat Kumar at the Asian Institute of Technology, this programme intended to map the geographic distribution of $P$. manihoti, assess its pest pressure in local cassava fields, chart its potential invasion pathways, and understand its relative importance in relation to other arthropod pests and plant diseases. Ultimately, the programme sampled more than 572 cassava fields over 2 years, covering areas as diverse as Viet Nam's Central Highlands, the Ayeyawaddy delta of Myanmar or the remote uplands of southern Lao PDR.

Survey protocols are described in detail in Graziosi et al. (2016). In brief, we randomly selected older fields ( $>5-6$ months old) in the main cassava-growing provinces within each country, with separate plots located at least $1 \mathrm{~km}$ apart. Surveys were carried out in January-May 2014 (dry season), October-November 2014 (late rainy season) and January-March 2015 (dry season). Location and elevation of each field were recorded using a handheld GPS unit (Garmin Ltd, Olathe, Kansas, USA). Per field, five linear transects were randomly chosen, with each transect covering 10 plants. By doing so, a total of 50 plants per field were assessed for P. manihoti infection status and associated 'bunchy top' symptoms (Neuenschwander et al. 1987), and per-plant mealybug abundance. In-field identification of mealybugs was based on morphological characters such as colour and length of abdominal waxy filaments. Following transect walks, we computed average $P$. manihoti infestation pressure (number of individuals per infected tip) and estimated field-level incidence of this pest (proportion of $P$. manihoti-affected tips, or 'bunchy tops') for each field.

Mealybugs are the most widespread group of arthropods on cassava crops in Southeast Asia, occurring in 70\% of cassava fields (Graziosi et al. 2016). In some countries, such as Myanmar and Thailand, mealybugs were found in 95 and $100 \%$ of the fields, respectively. In infested fields, mealybugs were found on $27 \pm 2 \%$ of plants, this representing the highest incidence among cassava-associated arthropods. The resident mealybug community on cassava was composed of 4 non-native species: (1) P. manihoti; (2) the papaya mealybug Paracoccus marginatus Williams \& Granara de Willink; (3) Pseudococcus jackbeardsleyi Gimpel \& Miller; and (4) the striped mealybug Ferrisia virgata Cockerell.

Within this mealybug community, $P$. manihoti represented $19.8 \%$ of the species complex ( $\mathrm{n}=572$ fields, across dry and rainy season), and was recorded from $37 \%$ of fields during the 2014 dry season. The cassava mealybug was recorded from fields across Cambodia and Thailand, and it was also recorded in southern parts of Lao PDR and Viet Nam (Fig. 1). Across sites and sampling events, $P$. manihoti was recorded at average incidence rates of $7.4 \pm 15.8 \%$ and dry-season abundance of $14.3 \pm 30.8$ individuals per infected tip. Maximum incidence rates were $100 \%$, and maximum field-level abundance was 366.6 mealybugs per tip. Field-level abundance and incidence rates were highly variable between settings and countries (Table 1). 


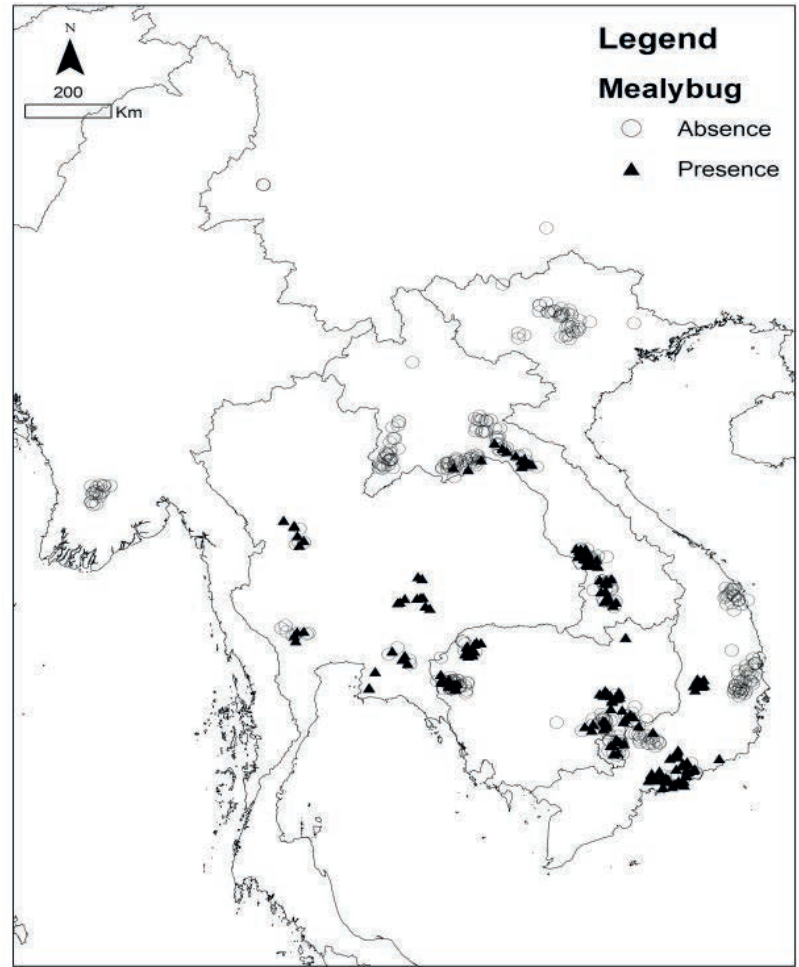

Figure 1. Geographic distribution of Phenacoccus manihoti, as recorded during 2014-15 surveillance across the Greater Mekong subregion.

Overall, in Asia's primary cassava cropping areas, current mealybug pest pressure was nearly identical to that in Africa during the mid-1980s. At the time, P. manihoti populations collapsed soon after parasitoid introduction and stabilized at incidence rates of $23 \%$ and abundance levels below 10 individuals per tip (Hammond and Neuenschwander 1990).

\section{PARASITOID ESTABLISHMENT, SPREAD AND INCIDENCE}

To assess $A$. lopezi establishment patterns and parasitism rates, and to delineate the parasitoid community associated with $P$. manihoti, we conducted two observational studies. First, over the course of two consecutive growing seasons, bi-monthly sampling was carried out in Tay Ninh, Viet Nam to characterize mealybug-parasitoid population dynamics (Le et al., unpublished). Second, dry-season sampling was done during 2014-2016 at a number of mealybug-invaded sites in eastern Cambodia $(\mathrm{n}=$ $15)$, eastern Thailand $(\mathrm{n}=20)$, and southern Viet Nam $(\mathrm{n}=19,40)$. In each experiment, sampling consisted of collecting a total of 20 mealybug-infested tips or 'bunchy tops' from local cassava fields that were transferred to the laboratory for subsequent assessment of parasitoid emergence. 
Table 1. Average incidence (percentage mealybug-infested plants per field; mean $\pm S D$ ) and abundance (number of individuals per infected tip) of Phenacoccus manihoti as recorded during multi-country surveillance in the 2014-15 growing seasons

\begin{tabular}{|c|c|c|c|c|c|c|}
\hline Country & Province & Date & Season & $\begin{array}{c}\text { Sample } \\
\text { size } \\
(n)\end{array}$ & $\begin{array}{c}\text { Incidence } \\
(\%)\end{array}$ & $\begin{array}{c}\text { Abundance } \\
\text { (\#/ tip) }\end{array}$ \\
\hline \multirow[t]{4}{*}{ Thailand } & Nakhon Ratchasima & Mar 2014 & Dry & 10 & $22.6 \pm 16.1$ & $16.3 \pm 18.5$ \\
\hline & Kampheang Phet & Mar 2014 & Dry & 9 & $3.8 \pm 5.2$ & $9.2 \pm 8.8$ \\
\hline & Chachoengsao & Mar 2014 & Dry & 9 & $2.9 \pm 4.7$ & $6.5 \pm 5.4$ \\
\hline & Kanchanaburi & Mar 2014 & Dry & 11 & $6.6 \pm 13.2$ & $37.0 \pm 58.9$ \\
\hline \multirow[t]{6}{*}{ Lao PDR } & Borikhamxay & Feb 2014 & Dry & 27 & $0.5 \pm 1.9$ & $1.7 \pm 1.5$ \\
\hline & Vientiane capital & Feb 2014 & Dry & 22 & $0.1 \pm 0.4$ & $1.0 \pm 0.0$ \\
\hline & Xiengkhuong & Jan 2014 & Dry & 6 & 0.0 & 0.0 \\
\hline & Xayabuli & Feb 2014 & Dry & 20 & 0.0 & 0.0 \\
\hline & Champasak & Feb 2014 & Dry & 25 & $4.2 \pm 11.1$ & $3.4 \pm 4.2$ \\
\hline & Salavan & Feb 2014 & Dry & 25 & $13.6 \pm 18.3$ & $6.3 \pm 9.6$ \\
\hline \multirow[t]{5}{*}{ Cambodia } & Banteay Meanchey & Feb 2014 & Dry & 20 & $13.8 \pm 11.9$ & $7.7 \pm 4.4$ \\
\hline & Kampong Cham & Feb 2014 & Dry & 20 & $6.7 \pm 18.2$ & $14.4 \pm 14.4$ \\
\hline & Pailin & Feb 2014 & Dry & 19 & $9.5 \pm 17.9$ & $5.5 \pm 3.9$ \\
\hline & Battambang & Mar 2014 & Dry & 20 & $0.3 \pm 0.9$ & $1.2 \pm 0.3$ \\
\hline & Kratie & Feb 2014 & Dry & 20 & $16.3 \pm 14.2$ & $24.7 \pm 26.5$ \\
\hline Myanmar & Ayeyawaddy & Apr 2014 & Dry & 20 & 0.0 & 0.0 \\
\hline \multirow[t]{10}{*}{ Viet Nam } & Dong Nai & Feb 2014 & Dry & 20 & $43.7 \pm 19.7$ & $32.5 \pm 14.6$ \\
\hline & Binh Phuoc & Apr 2014 & Dry & 21 & $3.0 \pm 13.4$ & $7.7 \pm 0.0$ \\
\hline & Ba Ria-Vung Tau & May 2014 & Rainy & 20 & $35.9 \pm 29.4$ & $11.1 \pm 17.0$ \\
\hline & Tay Ninh & May 2014 & Rainy & 21 & $5.0 \pm 8.2$ & $5.0 \pm 2.3$ \\
\hline & Phu Yen & Apr 2014 & Dry & 19 & 0.0 & 0.0 \\
\hline & Dak Lak & Mar 2015 & Dry & 10 & $11.6 \pm 6.4$ & $3.7 \pm 2.4$ \\
\hline & Quang Ngai & Apr 2014 & Rainy & 20 & 0.0 & 0.0 \\
\hline & Binh Thuan & Mar 2015 & Dry & 10 & $9.2 \pm 14.5$ & $7.1 \pm 12.8$ \\
\hline & Yen Bai & Oct 2014 & Rainy & 20 & 0.0 & 0.0 \\
\hline & Phu Tho & Oct 2014 & Rainy & 19 & 0.0 & 0.0 \\
\hline China & Yunnan & Nov 2014 & Rainy & 25 & 0.0 & 0.0 \\
\hline
\end{tabular}

Sampling procedures were adapted from Neuenschwander and Hammond (1988) and consisted of breaking off $20-\mathrm{cm}$ 'tips' of infested plants and placing these in sealed paper bags. Next, bags with plant material were transferred to the laboratory, where each tip was carefully examined and the total number of $P$. manihoti was counted. Next, cassava tips were individualized within transparent polyvinyl chloride (PVC) containers and covered with fine cotton fabric mesh. Over the course of 3 weeks, containers were stored at ambient conditions and inspected on a daily basis for emergence of parasitoid wasps. Next, parasitoids and potential hyperparasitoids were collected by aspirator and stored for subsequent identification.

In the first study, $P$. manihoti occurred at an average incidence of $24.8 \pm 17.7 \%$ and abundance level of $5.6 \pm 5.3$ individuals per tip across both growing seasons. In general, mealybug populations built up during the second half of the dry season and remained at low levels during the rainy season. High A. lopezi parasitism levels were recorded during each year, at average levels of $50.3 \%$ and $43.9 \%$ in rainy and dry season, respectively. Though rainfall does indeed cause high mortality of P. manihoti, 
it is believed that $A$. lopezi accounts for the sustained low mealybug population levels across seasons, through direct $P$. manihoti parasitism and host-feeding. The primary parasitoid community was entirely composed of $A$. lopezi, yet three potential hymenopterous hyperparasitoid species were also found from sites in Tay Ninh (Viet Nam): Chartocerus sp. near walkeri (Signiphoridae), Promuscidea unfasciativentris Girault (Eriaporidae) and Prochiloneurus sp. (Encyrtidae). Hyperparasitism levels were on average $2.8 \pm 5.4 \%$, with maximum rates of $26.4 \%$. In smallholder cassava fields in eastern Cambodia, the hyperparasitoid community was found to be more diverse and species-rich, though locally-recorded species remain to be identified (Wyckhuys et al. 2017c).

In the second study, A. lopezi was found in P. manihoti-affected fields in Cambodia, Thailand and Viet Nam at parasitism levels of $10-57 \%$, with an overall average of $38.9 \%$ (Wyckhuys et al. 2017b). Both studies exemplify how the introduced parasitoid has effectively colonized cassava fields in at least three Asian countries, attaining medium to high parasitism rates and contributing to P. manihoti control under a variety of agro-ecological conditions.

\section{MULTI-FACETED DETERMINANTS OF BIOLOGICAL CONTROL SUCCESS}

Field surveys and observational studies across the tropical Asia region have shown relatively low $P$. manihoti infestation levels, yet highly variable $A$. lopezi parasitism rates. For example, while $A$. lopezi attains dry-season parasitism of $16.3 \pm 3.4 \%$ in coastal Viet Nam, it attains rates of $52.9 \pm 4.3 \%$ in intensified cropping systems in the Tay Ninh province (Fig. 2).

To gain a better appreciation of potential constraints to $A$. lopezi success, we examined $P$. manihoti biological control through a number of different lenses, drawing on disciplines such as landscape ecology, plant pathology and soil science. Other factors, such as access to floral nectar and interference through tending ants are being investigated by A. Rauf and students in Indonesia, but they are not reported in this paper.

\subsection{Soil-Mediated Effects on Mealybug Biological Control}

Soil fertility and structure can determine plant health and shape overall resistance to pests (Amtmann et al. 2008), however, the impact of below-ground processes on above-ground interactions varies and is particularly difficult to predict. Also, alterations in plant nutrients are readily transmitted through trophic chains and affect the relative role of resource ("bottom-up") versus consumer ("top-down") forces in the structuring of ecological communities (Hunter and Price 1992). The success of both native and invasive herbivores has been explained through a range of theories and hypotheses, some of which simultaneously account for the role of the above plant resource availability and natural enemies (Blumenthal 2005; Center et al. 2014). Hence, understanding how certain herbivores (such as $P$. manihoti) and their associated parasitoids such as $A$. lopezi interact and respond to soil fertility and plant nutrient status is extremely valuable. 


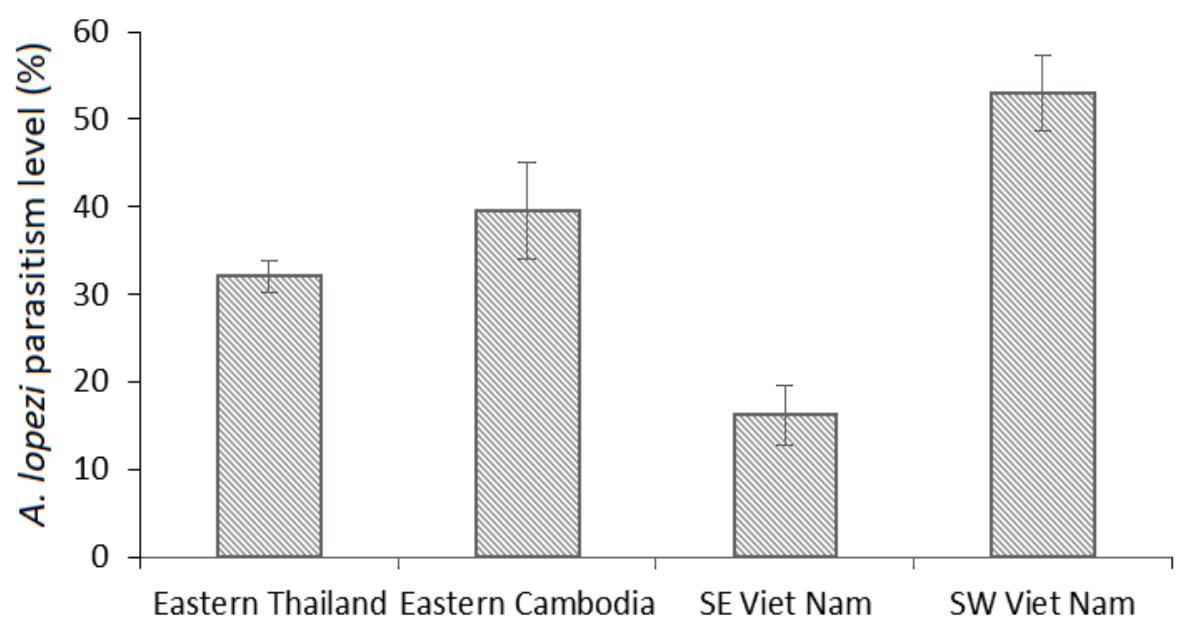

Figure 2. Parasitism levels (mean $\pm S D$ ) by Anagyrus lopezi, as recorded from selected fields in the invaded range of Phenacoccus manihoti (respective sample size: 20, 15, 19, 40).

During 2015-2016, a set of manipulative trials and observational studies were carried out to illuminate how soil fertility affects $P$. manihoti x A. lopezi interactions (Wyckhuys et al. 2017b). More specifically, potted-plant fertilizer trials were combined with a regional survey of 65 cassava fields with varying soil fertility. Pot trials revealed strong bottom-up effects for $P$. manihoti, with nitrogen and potassium addition equally boosting development and fitness of $A$. lopezi.

Field surveys indicate that mealybug performance is highly species-specific and context-dependent. For P. manihoti, in-field abundance is associated with soil texture, i.e. silt content, and mealybug populations are disproportionately favoured in lowfertility conditions. Parasitism by $A$. lopezi varied greatly with field and soil fertility conditions and was highest in soils with intermediate fertility levels and where management practices include the addition of fertilizer supplements.

These findings on the field context show how deficient soil management can further exacerbate mealybug pest problems and ultimately push farmers into 'poverty traps'. On the other hand, our work can help target additional biological control measures and inform management practices, such as mulching, organic matter addition, or corrective nutrient supplementation, to enhance or restore mealybug biological control.

Similar impact across several trophic levels had been documented also in Africa. In Malawi, for instance, biological control despite the presence of $A$. lopezi only failed in the few $(10 \%)$ fields on sandy, un-mulched soils that did not sustain leafy plants (Neuenschwander et al. 1991). 


\subsection{Plant-Microbe-Insect Interactions}

In recent years, scientific interest in plant-insect-microbe or 'cross-kingdom' interactions has boomed, steadily revealing the multiple, intricate ways in which micro-organisms mediate plant-herbivore interplay (Ponzio et al. 2013; Tack and Dicke 2013). Phytopathogens regularly alter whole repertoires of plant phenotypic traits, and they bring about shifts in key chemical or morphological characteristics of plant hosts (Tack et al. 2012; Biere and Tack 2013). Though largely overlooked, pathogens can also cause cascading effects on higher trophic levels and eventually shape entire plant-associated arthropod communities.

In an observational study in early 2016, I. Graziosi and Cambodian colleagues investigated whether a Candidatus Phytoplasma causing cassava witches' broom (CWB) is altering relative abundance and species composition of different invasive mealybugs and determines success of their associated parasitoids, including $A$. lopezi. The CWB is an emerging phytopathogen that occurs at near-pandemic levels in several parts of Southeast Asia, and which causes leaf discoloration, extensive proliferation of leaves and stems, and stunted growth. In their study, samples were taken from multiple sites of CWB-symptomatic and asymptomatic plants (Wyckhuys et al. 2007c). From each plant, the apical part or 'tip' was collected and transferred to the laboratory for further processing. After counting and identifying all mealybug individuals, each cassava tip was transferred individually to transparent PVC containers, closed with fabric mesh. Over a period of 14 days, containers were checked for emergence of parasitoids or hyperparasitoids. Parasitoids were identified to morpho-type and stored in ethanol for subsequent species-level identification. CWB infection was found to positively affect overall mealybug abundance and species richness, and to disproportionately favour the generalist Paracoccus marginatus over $P$. manihoti (Fig. 3).

Moreover, CWB phytoplasma infection was positively correlated with an increased parasitoid richness and diversity. Though overall parasitism rate did not differ among CWB-infected and uninfected plants, lower numbers of $A$. lopezi were obtained from infected plants. Also, CWB-infection status affected $A$. lopezi sex ratio, with more male-biased sex ratios on CWB-infected plants (Wyckhuys et al. 2017c). This possibly could be explained by smaller 'undernourished' mealybugs which are more often selected by females for male eggs.

This work underlines how systemic plant pathogens such as CWB do impact parasitoid establishment and efficacy, and how they could influence P. manihoti biological control. Hence, entomologists need to work across disciplines and take into consideration plant pathology aspects when assessing field-level parasitism rates and biological control success. 


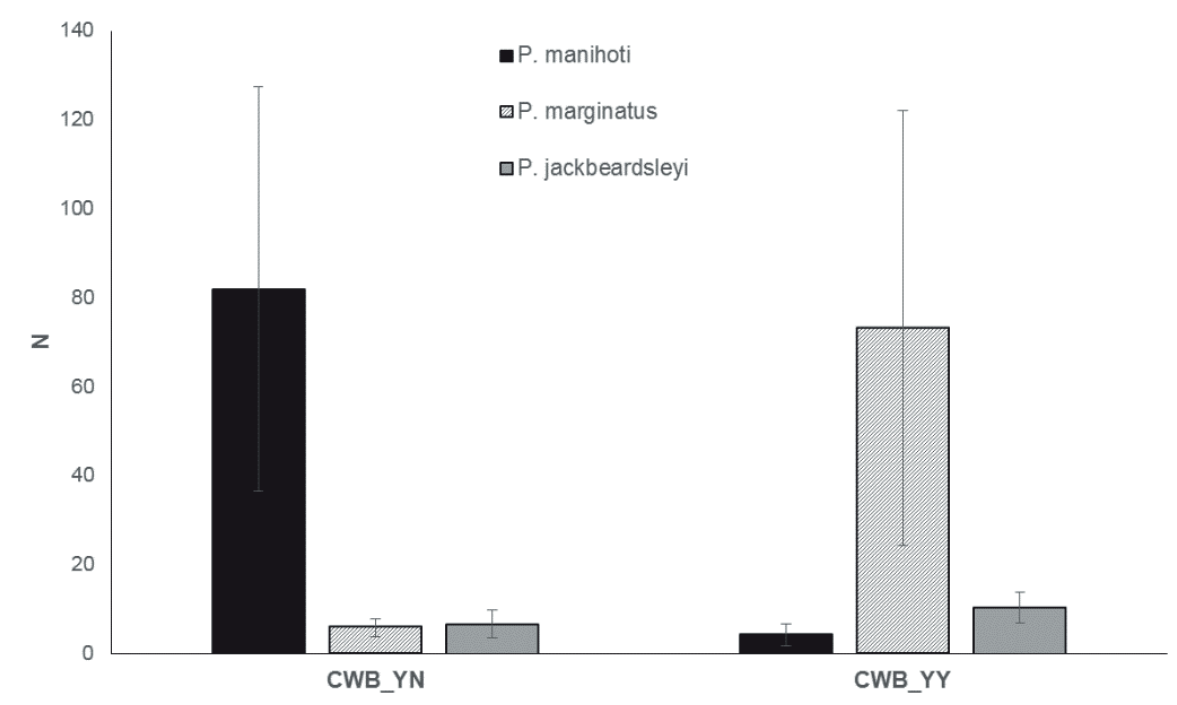

Figure 3. Plant-level abundance of different mealybug species on plants with characteristic symptoms of asymptomatic plants (CWB_YN) and cassava witches' broom (CWB_YY).

\subsection{Landscape-Level Drivers}

As exemplified in the above Sections, patch-level characteristics, such as soil fertility or plant disease pressure, greatly impact $A$. lopezi abundance and performance. On the other hand, landscape-level variables may equally affect biological control of invasive pests such as $P$. manihoti, though have rarely been taken into consideration.

The impact of landscape structure on natural enemy abundance, diversity, and activity in temperate cropping systems such as grains, canola or cabbage crops is fairly well documented (Bianchi et al. 2006; Chaplin-Kramer et al. 2011; Schellhorn et al. 2015), though much less is known about its overall impact on pest pressure or natural biological control. However, for specialist parasitoids such as A. lopezi, landscape simplification could be particularly disruptive (Cagnolo et al. 2009). Also, landscape complexity differentially benefits hyperparasitoids, which potentially could derail biological control of P. manihoti (Rand et al. 2012).

In mid-2013, T. T. N. Le and collaborators from Viet Nam's Plant Protection Department (VPPD) embarked upon a two-year study to assess mealybug x parasitoid population dynamics under varying landscape context (Le et al. 2018). Over the course of two consecutive cropping seasons, insect populations were surveyed under small-field and high-diversity or large-field and low-diversity landscape settings. In certain areas, cassava fields are small (1-2 ha in size), embedded within relatively complex and diverse landscape settings (here termed 'high-diversity' sites). Other landscape sectors are primarily made up of larger fields, ranging between 4 and 8 ha (here termed 'low-diversity' sites). Overall, P. manihoti colonized fields earlier and attained higher incidence in small plots within high-diversity landscapes as compared to large fields in simplified landscapes (Fig. 4). 
Landscape type, however, significantly affected hyperparasitism rate at certain crop ages, but did not impact $P$. manihoti abundance or $A$. lopezi parasitism rate. Also, a slightly more pronounced density-dependent response of $A$. lopezi was found within low-diversity settings, at a scale of both individual cassava tips and entire fields. These landscape-dependent impacts likely directly relate to dispersal modalities and other ecological traits of $A$. lopezi, including its supreme ecological plasticity, exceptional dispersal capacity and ability to equally host-feed and consume cassava extra-floral nectar (Neuenschwander 2001).
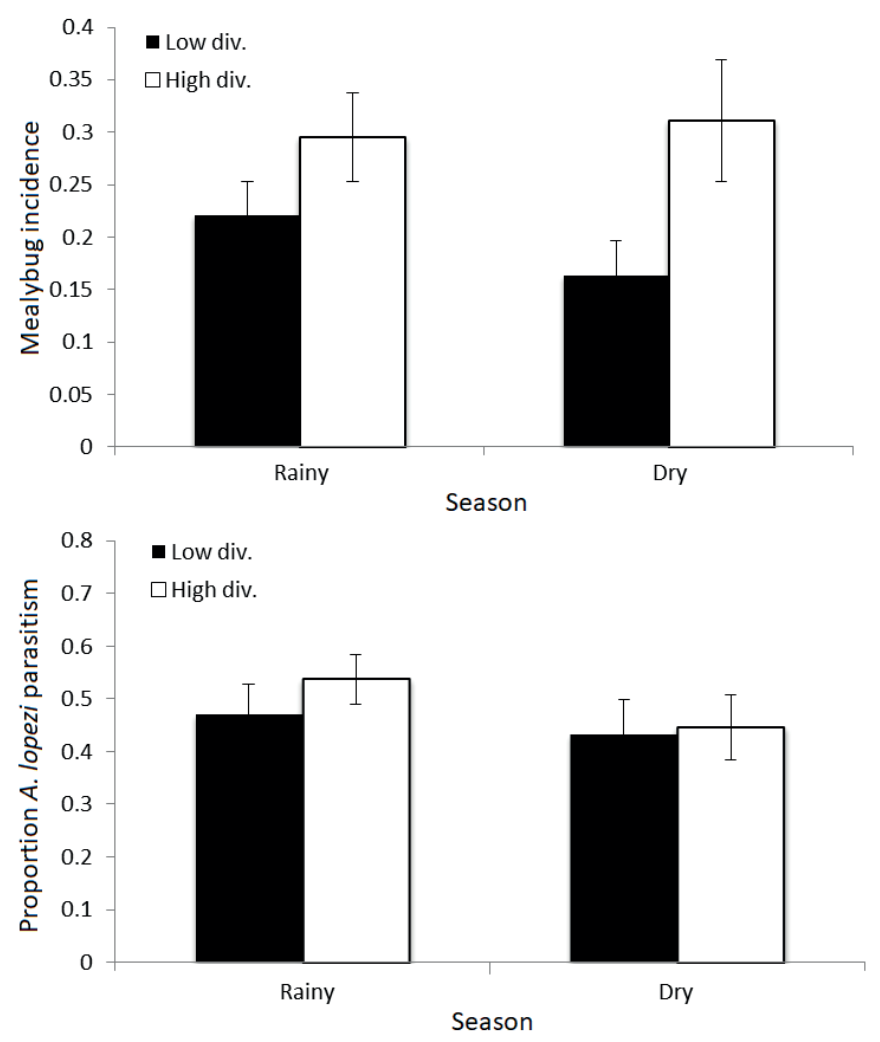

Figure 4. Phenacoccus manihoti incidence (proportion infected plants) and Anagyrus lopezi parasitism rate during dry and rainy season, for fields within high-and low-diversity landscape settings (see Le et al. 2018).

\section{SOCIAL SCIENCE: COMPASS AND PUBLIC AWARENESS FOR A REGIONAL BIOLOGICAL CONTROL CAMPAIGN}

Though regularly overlooked or roundly disregarded, social science is of paramount importance for the successful promotion of IPM, and particularly for effective biological insect control. More so, only a fraction of biological control studies over the past 25 years explicitly address social science or technology transfer aspects (Wyckhuys et al. 2017a). 
A retrospective analysis of social science studies from the developing-world tropics showed that most farmers have highly-deficient knowledge of natural enemies, and routinely express doubts about the exact value of biological control services on their farm. More so, farmers' knowledge of (fast-spreading) invasive pests and their control is considered to be exceptionally weak. These trends are worrying and could stifle farm-level adoption and subsequent diffusion of knowledge-intensive technologies such as biological control (Catalini and Tucker 2017).

Though classical biological control - as in the case of A. lopezi - is largely considered to be self-propelling and requires little or no intervention by farmers (Andrews et al. 1992), it is critical to build and strengthen farmers' agro-ecological knowledge in light of the active promotion of systemic insecticides for mealybug control. At the time of writing this chapter, hundreds of thousands of smallholder growers in one particular Asian country had embraced the use of prophylactic dips with neonicotinoids and considered those as a central component in their cassava crop management. These products cause long-term negative impacts on A. lopezi survival and fitness (Lankaew, Tan, Nguyen and Wyckhuys, unpublished), and as such they could hamper biological control.

In late 2014, a two-country survey was started to characterize agro-ecological knowledge, attitudes and pest management practices of local cassava growers (Uphadyay et al. 2018). A parallel study was done by A. Rauf and N. Wardani in Indonesia. In Lao PDR and Viet Nam, farmers had limited awareness of recent invasive pests, such as $P$. manihoti, and their knowledge was highly context- and locality-specific, i.e. shaped by the invasion history of the mealybug. Only the occasional farmer was aware of the existence of natural enemies on his/her farm, and even charismatic and important guilds such as lady beetles, spiders or lacewings were recognized by $<10 \%$ local growers. Overall, a minority of farmers used preventive tactics and in recently invaded fields frequently resorted to drastic measures such as overhead sprays of insecticides and burning of entire fields. In southern Viet Nam, women guide household-level IPM decision-making (Uphadyay et al. 2018), yet their weak agro-ecological knowledge base could further enable local diffusion of insecticide use.

To counteract some of the above trends and ease obstacles in farmer learning about biological control, a video-mediated extension campaign was launched. Farmer-tofarmer video is particularly suited to transfer complex concepts such as parasitism and insect predation, and it can help secure $P$. manihoti biological control in Asia's cassava systems. A farmer to farmer video was developed by carefully selecting farmers from the FAO-deployed Farmer Field Schools in eastern Thailand and documenting some of their successes with P. manihoti control. This allowed production of a multi-lingual video entitled 'Managing Mealybugs in Cassava' by the Belgium-based company AgroInsight. This video is available for streaming in English and multiple Asian languages through Access Agriculture (2019) or YouTube channels. This farmer-to-farmer video was subsequently distributed through multiple means, including private sector actors, national television and rural extension bureaus, reaching >200 000 growers in a matter of months in Viet Nam alone. 


\section{CONCLUSIONS}

This chapter aims at providing a comprehensive overview of the multi-institutional biological control programme against the invasive mealybug $P$. manihoti in cassava crops across mainland Southeast Asia. Two-year population surveys and area-wide pest surveillance reveal how $P$. manihoti has effectively spread to at least six Asian countries, yet occurs at low to intermediate incidence rates and at abundance levels of 10-20 individuals per tip. Though rainfall and humidity are responsible for important levels of mortality, $P$. manihoti is deemed to be under effective biological control by the introduced $A$. lopezi. Five years after its introduction in eastern Thailand, A. lopezi is presently recorded at high though variable population levels in most mealybuginvaded fields in the region. Although not covered in this chapter, chemical and physical exclusion assays have shown how the resulting $P$. manihoti infestation rates only have minor impact on cassava crop yield or harvest indices. Hence, the minute wasp that was originally sourced in southern Brazil and Paraguay in 1981, and released across Africa during the 1980s, now also brings relief to cassava farmers in tropical Asia. The impact of this biological control programme on farmer livelihoods, national economies and rural agro-industries still needs to be assessed, but the economic benefits are expected to equal and probably surpass the multi-billion dollar benefits that were estimated in Africa (Zeddies et al. 2001; Wyckhuys et al. 2018).

Some of the factors that underpinned the outright success of this tropical Asiawide biological control campaign are the following:

1. Globe-spanning collaboration between FAO, CABI and CGIAR institutions, plus ready access to insect biodiversity in countries such as Brazil and Paraguay, allowed the necessary foreign exploration and effective identification of suitable natural enemies. Next, a swift mobilization of government institutions in Thailand and the strong support from private sector actors such as TTDI proved to be of crucial importance in ensuring establishment and country-wide spread of $A$. lopezi.

2. Extension campaigns that were built upon a sound appreciation of farmers' knowledge, attitudes and practices across farming contexts and sites. Though conventional extension initiatives were effective in Thailand, a farmer-to-farmer educational video proved to be key to transferring growers' experiences, perceptions and innovations from early-adopters and Farmer Field School groups in invaded areas. This undoubtedly boosted preparedness and prevented certain detrimental practices - such as unguided use of insecticides - from gaining a foothold.

3. A near-exclusive focus on herbivore-natural enemy interactions at the level of a single plant is often adopted in today's biological control or IPM studies. Though this yields valuable insights into those particular trophic interactions, it regularly obscures other equally important mechanisms at different trophic, spatial or organizational scales. Hence, we advocate holistic, systems-level approaches that draw upon disciplines beyond conventional entomology or insect ecology.

4. Gaining a thorough understanding of the various factors that shape variability in parasitism not only is valuable from an ecological perspective, but it can equally guide efforts to improve biological control efficacy (Rosenheim 1998). Our assessment of determinants of $A$. lopezi parasitism pointed to options to enhance mealybug pest control through interventions targeting soil nutrients, landscape composition, plant diseases, or crop management scenarios (for the latter, see Delaquis et al. 2018). 
5. In September 2015, Nature Magazine (Volume 525) boldly stated that:

"to solve the grand challenges facing society and to save the world, scientists and social scientists must work together" (Nature 2015).

Interdisciplinary science matters (see also Brondizio et al. 2016), and our work underscores that fully collaborative, integrative research is central to effectively solve invasive pest problems and to advance AW-IPM and biological control in developingworld agriculture.

\section{ACKNOWLEDGEMENTS}

This work presents original data-sets that were generated through collaborative research by counterparts across tropical Asia, CIAT Asia personnel and international co-operators. The bulk of research was conducted as part of an EC-funded, IFADmanaged and CIAT-executed programme (CIAT-EGC-60-1000004285), while additional funding was provided through the CGIAR-wide Research Program on Roots, Tubers and Banana (CRP-RTB). Exploratory research on plant-insect-microbe interactions was carried out as part of a STINT project funded by the Swedish University of Agricultural Sciences (SLU).

\section{REFERENCES}

Access Agriculture. 2019. Managing mealybugs in cassava (video).

Andrews, K. L., J. W. Bentley, and R. D. Cave. 1992. Enhancing biological control's contributions to Integrated Pest Management through appropriate levels of farmer participation. Florida Entomologist 75: 429-439.

Amtmann, A., S. Troufflard, and P. Armengaud. 2008. The effect of potassium nutrition on pest and disease resistance in plants. Physiologia Plantarum 133: 682-691.

Bellotti, A. C., L. Smith, and S. L. Lapointe. 1999. Recent advances in cassava pest management. Annual Review of Entomology 44: 343-370.

Bellotti, A. C., B. V. Herrera, and G. Hyman. 2012. Cassava production and pest management: Present and potential threats in a changing environment. Tropical Plant Biology 5: 39-72.

Bianchi, F. J. J. A., C. J. H. Booij, and T. Tscharntke. 2006. Sustainable pest regulation in agricultural landscapes: A review on landscape composition, biodiversity and natural pest control. Proceedings of the Royal Society B - Biological Sciences 273: 1715-1727.

Biere, A., and A. J. M. Tack. 2013. Evolutionary adaptation in three-way interactions between plants, microbes and arthropods. Functional Ecology 27: 646-660.

Blumenthal, D., 2005. Interrelated causes of plant invasion. Science 310: 243-244.

Brondizio, E. S., K. O'Brien, X. Bai, F. Biermann, W. Steffen, F. Berkhout, C. Cudennec, M. C. Lemos, A. Wolfe, J. Palma-Oliveira, and C. T. A. Chen. 2016. Re-conceptualizing the Anthropocene: A call for collaboration. Global Environmental Change 39: 318-327.

Cagnolo, L., G. Valladares, A. Salvo, M. Cabido, and M. Zak. 2009. Habitat fragmentation and species loss across three interacting trophic levels: Effects of life-history and food-web traits. Conservation Biology 23: 1167-1175.

Catalini, C., and C. Tucker. 2017. When early adopters don't adopt. Science 357: 135-136.

Center, T. D., F. A. Dray, E. D. Mattison, P. W. Tipping, and M. B. Rayamajhi. 2014. Bottom-up effects on top-down regulation of a floating aquatic plant by two weevil species: The context-specific nature of biological control. Journal of Applied Ecology 51: 814-824.

Chaplin-Kramer, R., M. E. O'Rourke, E. J. Blitzer, and C. Kremen. 2011. A meta-analysis of crop pest and natural enemy response to landscape complexity. Ecology Letters 14: 922-932. 
Cramb, R., V. Manivong, C. J. Newby, K. Sothorn, and P. S. Sibat. 2017. Alternatives to land grabbing: Exploring conditions for smallholder inclusion in agricultural commodity chains in Southeast Asia. The Journal of Peasant Studies 44: 939-967.

Delaquis, E., S. de Haan, and K. A. G. Wyckhuys. 2018. On-farm diversity offsets environmental pressures in tropical agro-ecosystems: A synthetic review for cassava-based systems. Agriculture, Ecosystems and Environment 251: 226-235.

Graziosi, I., and K. A. G. Wyckhuys. 2017. Integrated management of arthropod pests of cassava: The case of Southeast Asia, pp. 1-26. In Hershey, C. (ed.), Achieving sustainable cultivation of cassava. Volume II. Burleigh Dodds, Swaston, Cambridge, UK. 300 pp.

Graziosi, I., N. Minato, E. Alvarez, D. T. Ngo, T. X. Hoat, T. M. Aye, J. M. Pardo, P. Wongtiem, and K. A. G. Wyckhuys. 2016. Emerging pests and diseases of South-east Asian cassava: A comprehensive evaluation of geographic priorities, management options and research needs. Pest Management Science 72: 1071-1089.

Hammond, W. N. O., and P. Neuenschwander. 1990. Sustained biological control of the cassava mealybug Phenacoccus manihoti (Homoptera: Pseudococcidae) by Epidinocarsis lopezi (Hymenoptera: Encyrtidae) in Nigeria. Entomophaga 35: 515-526.

Hammond, W. N. O., P. Neuenschwander, and H. R. Herren. 1987. Impact of the exotic parasitoid Epidinocarsis lopezi on the cassava mealybug (Phenacoccus manihoti) populations. In P. Neuenschwander, J. S. Yaninek, and H. R. Herren (eds.), Africa-wide biological control project of cassava pests. Insect Science and its Application 8: 887-891.

Herren, H. R., and P. Neuenschwander. 1991. Biological control of cassava pests in Africa. Annual Review of Entomology 36: 257-283.

Herren, H. R., P. Neuenschwander, R. D. Hennessey, and W. N. O. Hammond. 1987. Introduction and dispersal of Epidinocarsis lopezi (Hym., Encyrtidae), an exotic parasitoid of the cassava mealybug, Phenacoccus manihoti (Hom., Pseudococcidae), in Africa. Agriculture, Ecosystems and Environment 19: 131-144.

Hunter, M. D., and P. W. Price. 1992. Playing chutes and ladders: Heterogeneity and the relative roles of bottom-up and top-down forces in natural communities. Ecology 73: 724-732.

Le, T. T. N., I. Graziosi, T. M. Cira, M. W. Gates, L. Parker, and K. A. G. Wyckhuys. 2018. Landscape context does not constrain biological control of Phenacoccus manihoti in intensified cassava systems of southern Vietnam. Biological Control 121: 129-139.

Löhr, B., A. M. Varela, and B. Santos. 1990. Exploration for natural enemies of the cassava mealybug, Phenacoccus manihoti (Homoptera: Pseudococcidae), in South America for the biological control of this introduced pest in Africa. Bulletin of Entomological Research 80(4): 417-425.

Muniappan, R., B. M. Shepard, G. W. Watson, G. R. Carner, A. Rauf, D. Sartiami, P. Hidayat, J. V. K. Afun, G. Goergen, and A. K. M. Ziaur Rahman. 2009. New records of invasive insects (Hemiptera: Sternorrhyncha) in Southeast Asia and West Africa. Journal of Agricultural and Urban Entomology 26: 167-174.

Nature 2015. Why interdisciplinary research matters. Scientists must work together to save the world. A special issue asks how they can scale disciplinary walls. 17 September 2015. Nature 525: 305 .

Neuenschwander, P., 2001. Biological control of the cassava mealybug in Africa: A review. Biological Control 21: 214-229.

Neuenschwander, P., and W. N. O. Hammond. 1988. Natural enemy activity following the introduction of Epidinocarsis lopezi (Hymenoptera: Encyrtidae) against the cassava mealybug, Phenacoccus manihoti (Homoptera: Pseudococcidae) in southwestern Nigeria. Environmental Entomology 17: 894902.

Neuenschwander, P., W. N. O. Hammond, and R. D. Hennessey. 1987. Changes in the composition of the fauna associated with the cassava mealybug, Phenacoccus manihoti, following the introduction of the parasitoid Epidinocarsis lopezi. Insect Science and its Application 8: 893-898.

Neuenschwander, P., R. Borowka, G. Phiri, H. Hammans, S. Nyirenda, E. H. Kapeya, and A. Gadabu. 1991. Biological control of the cassava mealybug Phenacoccus manihoti (Hom., Pseudococcidae) by Epidinocarsis lopezi (Hym., Encyrtidae) in Malawi. Biocontrol Science and Technololgy 1: 297-310.

Nwanze, K. F. 1982. Relationships between cassava root yields and crop infestations by the mealybug, Phenacoccus manihoti. International Journal of Pest Management 28: 27-32.

Parsa, S., T. Kondo, and A. Winotai. 2012. The cassava mealybug (Phenacoccus manihoti) in Asia: First records, potential distribution, and an identification key. PLoS One 7(10): e47675.

Ponzio, C., R. Gols, C. M. J. Pieterse, and M. Dicke. 2013. Ecological and phytohormonal aspects of plant volatile emission in response to single and dual infestations with herbivores and phytopathogens. Functional Ecology 27: 587-598. 
Rand, T. A., F. J. Van Veen, and T. Tscharntke. 2012. Landscape complexity differentially benefits generalized fourth, over specialized third, trophic level natural enemies. Ecography 35: 97-104.

Rosenheim, J. A. 1998. Higher-order predators and the regulation of insect herbivore populations. Annual Review of Entomology 43: 421-447.

Saengyot, S., and I. Burikam. 2012. Bionomics of the apefly, Spalgis epius (Lepidoptera: Lycaenidae), predatory on the papaya mealybug, Paracoccus marginatus (Hemiptera: Pseudococcidae) in Thailand. Songklanakarin Journal of Science and Technology 34: 1-7.

Sartiami, D., G. W. Watson, M. N. M. Roff, M. Y. Hanifah, and A. B. Idris. 2015. First record of cassava mealybug, Phenacoccus manihoti (Hemiptera: Pseudococcidae), in Malaysia. Zootaxa 3957: 235-238.

Sattayawong, C., S. Uraichuen, and W. Suasa-ard. 2016. Larval preference and performance of the green lacewing, Plesiochrysa ramburi (Schneider) (Neuroptera: Chrysopidae), on three species of cassava mealybugs (Hemiptera: Pseudococcidae). Agriculture and Natural Resources 50: 460-464.

Schellhorn, N. A., H. R. Parry, S. Macfadyen, Y. Wang, and M. P. Zalucki. 2015. Connecting scales: Achieving in-field pest control from areawide and landscape ecology studies. Insect Scien. 22: 35-51.

Schulthess, F., J. U. Baumgärtner, V. Delucchi, and A. P. Gutierrez. 1991. The influence of the cassava mealybug, Phenacoccus manihoti Mat.-Ferr. (Homoptera: Pseudococcidae) on yield formation of cassava, Manihot esculenta Crantz. Journal of Applied Entomology 111: 155-165.

Tack, A. J. M., and M. Dicke. 2013. Plant pathogens structure arthropod communities across multiple spatial and temporal scales. Functional Ecology 27: 633-645.

Tack, A. J. M., S. Gripenberg, and T. Roslin. 2012. Cross-kingdom interactions matter: Fungal-mediated interactions structure an insect community on oak. Ecology Letters 15: 177-185.

(TTTA) Thai Tapioca Trade Association. 2011. Annual report. Bangkok, Thailand.

Uphadyay, B., D. D. Burra, T. T. Nguyen, and K. A. G. Wyckhuys. 2018. Caught off guard: Folk knowledge proves deficient when addressing invasive pests in Asian cassava systems. Environment, Development and Sustainability 15(5): 1-21.

Winotai, A., G. Goergen, M. Tamo, and P. Neuenschwander. 2010. Cassava mealybug has reached Asia. Biocontrol News and Information 31: 10N-11N.

Wyckhuys, K. A. G., A. Rauf, and J. Ketelaar. 2015. Parasitoids introduced into Indonesia: Part of a region-wide campaign to tackle emerging cassava pests and diseases. Biocontrol News and Information 35: $29 \mathrm{~N}-38 \mathrm{~N}$.

Wyckhuys, K. A. G., J. W. Bentley, R. Lie, T. T. N. Le, and M. Fredrix. 2017a. Maximizing farm-level uptake and diffusion of biological control innovations in today's digital era. BioControl 63: 133-148.

Wyckhuys, K. A. G., D. D. Burra, D. H. Tran, I. Graziosi, A. J. Walter, T. G. Nguyen, H. N. Trong, B. V. Le, T. T. N. Le, and S. J. Fonte. 2017b. Soil fertility regulates invasive herbivore performance and top-down control in tropical agro-ecosystems of Southeast Asia. Agriculture, Ecosystems and Environment 249: 38-49.

Wyckhuys, K. A. G., I. Graziosi, I., D. D. Burra, and A. J. Walter. 2017c. Phytoplasma infection of a tropical root crop triggers bottom-up cascades by favoring generalist over specialist herbivores. PLoS One 12(8): e0182766.

Wyckhuys, K., W. Zhang, S. Prager, D. Kramer, E. Delaquis, C. Gonzalez, and W. van der Werf. 2018. Biological control of an invasive pest eases pressures on global commodity markets. Environmental Research Letters 13(9): 094005.

Yonow, T., D. J. Kriticos, and N. Ota. 2017. The potential distribution of cassava mealybug (Phenacoccus manihoti), a threat to food security for the poor. PLoS One 12(3): e 0173265.

Zeddies, J., R. P. Schaab, P. Neuenschwander, and H. R. Herren. 2001. Economics of biological control of cassava mealybug in Africa. Agricultural Economics 24: 209-219. 